\title{
EDUCAÇÃO MUSICAL E TRANSTORNO DO ESPECTRO AUTISTA: ANÁLISE DA PRODUÇÃO EM REVISTAS BRASILEIRAS DE ARTES/MÚSICA QUALIS A1 E SEUS ANAIS DE EVENTOS REGIONAIS E NACIONAIS (2006-2016)
}

\author{
Music education and autistic spectrum disorder: analysis of the \\ production in the brazilian magazines Qualis A1 of Arts / Music \\ Qualis A1 and its regional and national's events annals (2006-2016)
}

PAULYANE NASCIMENTO ZIMMER
Universidade Federal do Pará (UFPA)
paulyanenascimento @gmail.com
JÉSSIKA CASTRO RODRIGUES
Universidade Federal do Pará (UFPA)
jessika.rodrigues@uol.com.br
ÁUREO DÉO DEFREITAS
Universidade Federal do Pará (UFPA)
aureo_freitas@yahoo.com

\begin{abstract}
Resumo: Neste estudo, os pesquisadores analisam a produção gratuita sobre educação musical e Transtorno do Espectro Autista (2006-2016) nas revistas brasileiras Qualis A1 Artes/Música (avaliação 2014): (a) Música HODIE, Per Musi, ABEM e OPUS, e (b) Anais Regionais e Nacionais da ABEM e Nacionais da ANPPOM, descrevendo os enfoques/procedimentos de ensino. Com uma abordagem qualitativa e uma análise descritiva, esta pesquisa levantou 3.844 artigos, sendo 16 fidedignos à temática. Os pesquisadores apontam: a região Norte como a que tem mais pesquisas na área; a importância do perfil dos professores/monitores para ensino; necessidade de suporte aos profissionais; compreensão do transtorno e perfil do educando; adaptações curriculares e práticas; acompanhamento dos pais nos estudos; conscientização dos pares; uso de repetição, reforço contingente, dicas visuais e verbais; atividades que respeitem fases do desenvolvimento humano e musical; e possibilidades dos métodos Kodály, Orff, Suzuki, String Project, Dalcroze e Willems. Observaram-se estratégias promissoras, porém necessidade de atualização dos sites e mais aprofundamento nas pesquisas.
\end{abstract}

Palavras-chave: Educação Musical. Autismo. Pedagogia Musical.

\begin{abstract}
In this study, the researchers analyze the free production of Music Education and Autism Spectrum Disorder (2006-2016) in the Brazilian Magazines qualis A1 of Arts / Music (evaluation 2014): (a) Música HODIE, Per Musi, ABEM and OPUS, and (b) Regional and National's Events Annals ABEM and National's Events ANPPOM, describing approaches / teaching procedures. With a qualitative approach and descriptive analysis, this survey raised 3,844 articles, being 16 reliable to the thematic. The researchers indicate: the North region how that with more research in the in the area; the importance of the profile of teachers / monitors for teaching; need for professional support; understanding of the disorder and the profile of the student; curricular adaptations and practices; parental monitoring of studies; peer awareness; use of repetition, contingent reinforcement, visual and verbal cues; activities that respect stages of human and musical development; and, possibilities of the methods by Kodály, Orff, Suzuki, String Project, Dalcroze e Willems. There were promising strategies, but the need to update the sites and further research.
\end{abstract}

Keywords: Musical Education. Autism. Musical Pedagogy. 


\section{O TRANSTORNO DO ESPECTRO AUTISTA E A EDUCAÇÃO MUSICAL}

Em 2014, foi lançada a quinta edição do Manual Diagnóstico e Estatístico de Transtornos Mentais (DSM-5), a partir do qual nuances diagnósticas com características comuns passaram a chamar-se Transtorno do Espectro Autista (TEA), a saber: Transtorno Autista, Transtorno Desintegrativo da Infância, Transtorno Generalizado do Desenvolvimento Não-Especificado (PDD-NOS) e Sindrome de Asperger (APA, 2014).

A identificação do TEA no DSM-5 é descrita em níveis de gravidade de 1 a 3 , por ordem crescente de prejuizos (conforme necessidade de apoio) concernentes à comunicação social e aos comportamentos restritos e repetitivos, os quais podem variar de acordo com características do indivíduo (nível do desenvolvimento e idade cronológica) e do contexto, ou oscilar com o tempo. Além disso, ao se trabalhar com a música, é importante conhecer a possibilidade de hiper (alta) ou hiporreatividade (baixa reatividade) a estímulos sensoriais em pessoas com TEA "[...] manifestada por meio de respostas $[\ldots]$ a sons e texturas especificos, cheirar ou tocar objetos de forma excessiva, encantamento por luzes ou objetos giratórios e, algumas vezes, aparente indiferença à dor, calor ou frio" (APA, 2014, p. 54).

No TEA, áreas de processamento de sons não são afetadas pelo transtorno, o que indica uma porta de entrada à chamada Plasticidade Cerebral. Assim, ao se expor a pessoa com este diagnóstico a experiências musicais, pode-se aumentar as possiveis conexões neuronais em áreas responsáveis pela comunicação, interação social e motricidade, contribuindo para que a música auxilie na forma de apresentação dos sintomas (Rocha; Boggio, 2013).

No tocante à educação musical, Louro $(2012$, p. 43) defende que "[...] há caminhos e possibilidades para se alcançar resultados de boa qualidade musical inclusiva, contanto que o professor se prepare antecipadamente". Para esta autora, os pré-requisitos para um bom professor atender educacionalmente as pessoas com deficiência são:

- Quebra das barreiras atitudinais;

- Conhecimento mais profundo das deficiências;

- Conhecimento pormenorizado do aluno;

- Intercâmbio de informações;

- Definição clara e realista das metas pedagógicomusicais;

- Estratégias diferenciadas para as aulas e avaliações. (Louro, 2012, p. 43)

Em relação à educação musical, percebe-se que as variedades de perfis e limitações das pessoas com TEA lançam sobre o público docente a necessidade de adquirir habilidades para adaptação de tarefas e condução efetiva do processo educativo, a fim de atingir os objetivos propostos 
contemplando tanto alunos típicos quanto alunos com diagnósticos específicos.

\section{SOBRE A PESQUISA}

O objetivo geral dos pesquisadores deste estudo consistiu em analisar a produção científica brasileira sobre educação musical e TEA no período de 2006 a 2016 nas revistas de educação musical com Qualis A1 na área Artes/Música (avaliação 2014) e em seus anais de eventos regionais e nacionais disponibilizados em plataformas de acesso gratuito. Os objetivos específicos foram: a) identificar o enfoque das produções científicas brasileiras sobre educação musical e TEA neste período; b) descrever os procedimentos de ensino (métodos, materiais e técnicas) aplicados à educação musical de pessoas com TEA neste período.

Os procedimentos técnicos da pesquisa partiram de um levantamento bibliográfico acerca da referida temática com abordagem qualitativa e de natureza aplicada. De acordo com Triviños (1987, p. 100),

O processo de avaliação do material bibliográfico que o pesquisador encontra lhe ensinará até onde outros investigadores têm chegado em seus esforços, os métodos empregados, as dificuldades que tiveram de enfrentar, o que pode ser ainda investigado etc. Ao mesmo tempo, irá avaliando seus recursos humanos e materiais, as possibilidades de realização de seu trabalho, a utilidade que os resultados alcançados podem emprestar a determinada área do saber e da ação. E como dizem Selltiz et alii, a revisão permitirá descobrir as ligações do assunto que lhe interessa com outros problemas, o que, sem dúvida alguma, ampliará a visão sobre o tópico que se pretende estudar.

É nesse sentido que no presente estudo foi realizado um levantamento que busca oferecer aos profissionais leitores e/ou às demais pessoas interessadas acesso a um material compilado que poderá apresentar e fomentar discussões sobre o ensino da música para crianças com TEA.

No que compete à pesquisa qualitativa de natureza aplicada, Gerhardt e Silveira (2009, p. 35) explicitam que esta "Objetiva gerar conhecimentos para aplicação prática, dirigidos à solução de problemas específicos. Envolve verdades e interesses locais".

Quanto à coleta de dados, para selecionar as fontes realizou-se, por meio da Plataforma Sucupira, o levantamento dos periódicos brasileiros de qualificação A1 (Artes/Música - avaliação do ano de 2014), com enfoque em assuntos relacionados à música, educação musical e/ou suas interfaces, verificando-se o número de artigos direcionados à temática. Das quatro revistas selecionadas, duas se encontravam vinculadas a associações cujos eventos apresentavam publicações de anais e, por tal motivo, elencaram-se também como fontes da pesquisa os anais da Associação Nacional de 
Pesquisa e Pós-graduação em Música (ANPPOM) e os anais da Associação Brasileira de Educação Musical (ABEM). No Quadro 1, a seguir, encontramse os nomes das revistas Qualis A1 e dos anais que foram fonte desta pesquisa, bem como o número de produções encontradas sobre a temática.

\begin{tabular}{c|c|c|c}
\hline $\begin{array}{c}\text { Nome do } \\
\text { periódico }\end{array}$ & $\begin{array}{c}\text { Enfoque na área } \\
\text { Artes/Música }\end{array}$ & $\begin{array}{c}\text { Artigos } \\
\text { publicados } \\
(\mathbf{2 0 0 6 - 2 0 1 6 )}\end{array}$ & $\begin{array}{c}\text { Artigos } \\
\text { publicados } \\
\text { Música/TEA }\end{array}$ \\
\hline $\begin{array}{c}\text { Música } \\
\text { HODIE }\end{array}$ & Música geral & $\mathbf{2 1 5}$ & 0 \\
\hline $\begin{array}{c}\text { OPUS (Porto } \\
\text { Alegre) }\end{array}$ & Música geral & 176 & 0 \\
\hline $\begin{array}{c}\text { Per Musi } \\
\text { (UFMG) }\end{array}$ & Música e interfaces & 265 & 0 \\
\hline $\begin{array}{c}\text { Revista da } \\
\text { ABEM }\end{array}$ & Educação musical & 236 & 1 \\
\hline $\begin{array}{c}\text { Anais da } \\
\text { ABEM }\end{array}$ & Música e interfaces & $\begin{array}{c}\text { Encontros/Congressos } \\
\text { anuais }=1557\end{array}$ \\
\hline $\begin{array}{c}\text { Anais da } \\
\text { ANPPOM }\end{array}$ & Música e interfaces & Encontros nacionais $=891$ & 7 \\
\hline
\end{tabular}

Quadro 1: Quantitativo de artigos publicados em periódicos de qualificação Qualis A1 na área Artes/Música (Avaliação 2014) e anais da ABEM e ANPPOM. Fonte: PLATAFORMA SUCUPIRA e anais ABEM e ANPPOM.

Das fontes acima, todos os artigos com títulos e palavras-chave relacionados à educação musical inclusiva e/ou a pessoas com TEA tiveram seus resumos lidos pelos autores desta pesquisa para que não se perdessem publicações referentes à temática (caso o artigo, porventura, não trouxesse referência ao público investigado, seja no título ou nas palavras-chave). Após a leitura dos resumos, foram analisados na integra somente os que respondiam à temática, descartando-se aqueles direcionados aos aspectos terapêuticos da música.

O procedimento de análise dos dados obedeceu ao formato descritivo, com organização e discussão das informações coletadas. Para a organização dos dados, realizou-se a leitura dos artigos selecionados, cujos dados foram dimensionados em uma planilha, sendo explicitado: ano de publicação, nome dos autores, tipo de pesquisa, local de execução da pesquisa, número de participantes, delineamento de pesquisa, metodologia, objetivos, principais resultados, limitações. Depois, organizou-se um panorama dos resultados desses estudos com enfoque em métodos, materiais e técnicas, utilizados para viabilizar a aprendizagem musical de pessoas com TEA. 


\section{RESULTADOS}

Abordagens sobre o TEA têm crescido exponencialmente, em todas as áreas, dadas as implicações desenvolvimentais das características deste quadro clínico, a ampliação de ferramentas diagnósticas e a capacitação de profissionais de diversas áreas para avaliação e tratamento deste. Nesse sentido, é crucial que pesquisadores de educação musical e TEA possam formalizar a divulgação de resultados de seus trabalhos nesta área em revistas de grande alcance e com critérios científicos confiáveis.

Entre 2006 e 2016, no entanto, de um total de 3.844 artigos publicados, 892 encontram-se nas revistas Música HODIE, OPUS, PER MUSI e ABEM, dos quais somente um trata sobre educação musical e TEA. Achados nos anais de eventos científicos da $A B E M$ e da $A N P P O M$ (2.952 artigos), por sua vez, registram 15 artigos envolvendo o público-alvo do estudo, sendo 12 na $A B E M$ e 5 na $A N P P O M$.

Este resultado mostra-se alarmante, uma vez que as revistas de Qualis A1 são os maiores veículos de informações científicas de ponta, segundo os critérios da CAPES. Além disso, deve-se deixar claro o que foi exposto no próprio site da Fundação CAPES: "Não se realiza, desde 2009, qualificação de eventos, apenas de periódicos e livros. Estão suspensas temporariamente quaisquer informações sobre eventos" (QUALIS, 2017). Portanto, há o desconhecimento da comunidade científica acerca da qualificação das produções em eventos dentro dos critérios da CAPES.

Quanto aos anais dos encontros/congressos anuais da ABEM, os dados revelaram a ausência de três edições (XXVI, XX e XXIII) que não se encontravam disponiveis para download; no entanto, o acesso aos anais da edição XX (ano 2011) foi possivel devido à disponibilização do mesmo por um professor da Universidade do Estado do Pará. Portanto, o total de artigos encontrados sobre a temática pode ser alterado quando do acesso a todos os anais.

No que se refere aos encontros regionais da ABEM, com edições nas cinco regiões brasileiras, encontram-se disponibilizados no site apenas alguns anais - nem todos estão citados, observando-se lacunas entre as edições, bem como ausência de documentos para download. Nesse sentido, a Tabela 1, a seguir, apresenta somente as informações disponibilizadas no site.

\begin{tabular}{cccccc}
\hline Regiões & Ano & Edição & Cidade & $\begin{array}{c}\text { Número de } \\
\text { artigos } \\
\text { (Geral) }\end{array}$ & $\begin{array}{c}\text { Número de } \\
\text { artigos } \\
\text { (Música/TEA) }\end{array}$ \\
\hline Sudeste & 2007 & $\mathrm{~V}$ & São Paulo (SP) & $\begin{array}{c}\text { Anais não } \\
\text { disponiveis }\end{array}$ & $\begin{array}{c}\text { Anais não } \\
\text { disponiveis }\end{array}$
\end{tabular}




\begin{tabular}{|c|c|c|c|c|c|}
\hline & 2012 & VIII & São Paulo (SP) & $\begin{array}{c}\text { Anais não } \\
\text { disponiveis }\end{array}$ & $\begin{array}{l}\text { Anais não } \\
\text { disponíveis }\end{array}$ \\
\hline & 2014 & IX & Vitória (ES) & 71 & 2 \\
\hline \multirow[t]{4}{*}{ Sul } & 2007 & $\mathrm{X}$ & Blumenau (SC) & $\begin{array}{c}\text { Anais não } \\
\text { disponiveis }\end{array}$ & $\begin{array}{l}\text { Anais não } \\
\text { disponiveis }\end{array}$ \\
\hline & 2008 & $\mathrm{XI}$ & Santa Maria (RS) & $\begin{array}{c}\text { Anais não } \\
\text { disponiveis }\end{array}$ & $\begin{array}{l}\text { Anais não } \\
\text { disponiveis }\end{array}$ \\
\hline & 2012 & $\mathrm{XV}$ & Montenegro (RS) & $\begin{array}{l}\text { Anais não } \\
\text { disponiveis }\end{array}$ & $\begin{array}{l}\text { Anais não } \\
\text { disponiveis }\end{array}$ \\
\hline & 2014 & XVI & Blumenau (SC) & $\begin{array}{c}\text { Anais não } \\
\text { disponiveis }\end{array}$ & $\begin{array}{l}\text { Anais não } \\
\text { disponiveis }\end{array}$ \\
\hline \multirow[t]{2}{*}{ Norte } & 2012 & VII & Belém (PA) & 41 & 2 \\
\hline & 2014 & VIII & Rio Branco (AC) & 24 & 0 \\
\hline \multirow[t]{6}{*}{ Nordeste } & 2006 & V & Aracaju (SE) & $\begin{array}{c}\text { Anais não } \\
\text { disponiveis }\end{array}$ & $\begin{array}{l}\text { Anais não } \\
\text { disponiveis }\end{array}$ \\
\hline & 2007 & VI & Aracaju (SE) & $\begin{array}{c}\text { Anais não } \\
\text { disponiveis }\end{array}$ & $\begin{array}{l}\text { Anais não } \\
\text { disponiveis }\end{array}$ \\
\hline & 2008 & VII & João Pessoa (PB) & $\begin{array}{l}\text { Anais não } \\
\text { disponiveis }\end{array}$ & $\begin{array}{l}\text { Anais não } \\
\text { disponiveis }\end{array}$ \\
\hline & 2011 & $\mathrm{X}$ & Recife (PE) & 100 & 0 \\
\hline & 2012 & XI & Fortaleza $(\mathrm{CE})$ & 89 & 0 \\
\hline & 2014 & $\mathrm{XII}$ & São Luís (MA) & 119 & 1 \\
\hline \multirow[t]{6}{*}{$\begin{array}{l}\text { Centro- } \\
\text { Oeste }\end{array}$} & 2006 & VI & Goiânia (GO) & $\begin{array}{l}\text { Anais não } \\
\text { disponiveis }\end{array}$ & $\begin{array}{l}\text { Anais não } \\
\text { disponiveis }\end{array}$ \\
\hline & 2007 & VII & Cuiabá (MT) & $\begin{array}{l}\text { Anais não } \\
\text { disponiveis }\end{array}$ & $\begin{array}{l}\text { Anais não } \\
\text { disponiveis }\end{array}$ \\
\hline & 2008 & VIII & Brasília (DF) & $\begin{array}{l}\text { Anais não } \\
\text { disponiveis }\end{array}$ & $\begin{array}{l}\text { Anais não } \\
\text { disponiveis }\end{array}$ \\
\hline & 2012 & XII & Brasília (DF) & 32 & 0 \\
\hline & 2014 & XIII & $\begin{array}{l}\text { Campo Grande } \\
\text { (MS) }\end{array}$ & 28 & 0 \\
\hline & & & TOTAL & 504 & 5 \\
\hline
\end{tabular}

Tabela 1: Levantamento do número de artigos nos encontros regionais da ABEM (2006-2016). Fonte: Associação Brasileira de Educação Musical. Tabela organizada pelos autores deste trabalho.

No que diz respeito aos encontros nacionais da ANPPOM, observou-se a divulgação de todos os anais do período que compreende a pesquisa (2006 a 2016), porém houve uma grande oscilação de número de trabalhos publicados por evento, os quais variavam entre 37 a 316, encontrando-se somente três abordando o TEA e a educação musical. 


\section{ANÁLISES E DISCUSSÕES}

O levantamento realizado pelos autores da presente pesquisa nas revistas brasileiras Qualis A1 em Artes/Música e em anais de eventos da ABEM e da ANPPOM, de 2006 a 2016, revelou que estudos sobre TEA e educação musical foram encontrados somente a partir de 2011 , registrandose: três artigos em 2011; quatro em 2012; quatro em 2013; três em 2014 e dois em 2016. Deve-se enfatizar, quanto à fonte de dados de encontros da ABEM e da ANPPOM, a ausência de anais de algumas edições ou omissão destas, o que pode indicar a possibilidade de alteração no número de artigos encontrados, havendo, pois, necessidade dessas bases de dados serem atualizadas, a fim de serem disponibilizadas ao público as produções científicas disseminadas nesses eventos.

Quanto à localização das produções, verificou-se, no Sudeste, o número de quatro artigos publicados; no Sul, dois; no Nordeste, um; e a publicação de um artigo de Gomes (2014) que não menciona o estado do qual o autor é oriundo. A predominância de estudos ocorreu na região Norte, totalizando oito publicações, entretanto constatou-se a presença da utilização dos mesmos dados em duas publicações, com poucas alterações de abordagem, a saber, Rodrigues, Pereira e DeFreitas (2012) e Rodrigues e Pereira (2011), não havendo notas de rodapé ou informações que justificassem esta duplicata.

Acerca do tipo de pesquisa e do público investigado nos estudos sobre TEA, dos 16 artigos analisados, observou-se que 12 eram estudos de caso e 4, pesquisas bibliográficas. Dos estudos de caso, seis referiam-se a crianças ( 3 anos e 1 mês a 11 anos); dois ao público adolescente (13 a 18 anos); um ao público adulto (23 a 50 anos); um com participantes com faixas etárias diferentes (entre 5 e 14 anos); e dois artigos com as idades dos participantes não divulgadas.

Quanto aos estudos bibliográficos, dos quatro, três centraram-se na educação musical para crianças (Alves, 2014; Gomes, 2014; Borges; Monteiro, 2012), e o único trabalho sem enfoque de público tratou da investigação da educação musical aliada a aspectos psicomotores e simbólicos do ser humano (Blumer, 2016).

No que tange aos títulos, constatou-se que somente dois artigos não traziam referência ao público investigado, a saber, "Música e Inclusão: relato de experiência em uma turma de percussão infantil" (Oliveira et al., 2012) e "Programa de Apoio Pedagógico e Inclusão: um estudo de caso" (Soares, 2012). Dessa forma, é importante conscientizar os pesquisadores sobre a necessidade de apresentar, já em seus títulos, este público a fim de facilitar a localização das produções.

Quanto às palavras-chave, notou-se nos artigos a referência ao público com TEA a partir dos seguintes descritores: Sindrome de Asperger, Autismo, TEA, criança autista, adolescentes com autismo e Transtorno do Espectro Autista. É importante apontar que, no artigo intitulado "Programa de Apoio 
Pedagógico e Inclusão: um estudo de caso" (Soares, 2012), nenhuma palavrachave faz referência ao público com TEA. Neste caso, o acesso só foi possivel devido à leitura do resumo. Cita-se ainda um artigo que, apesar de especificar em seu título o público em estudo, não o referencia em suas palavras-chave, a saber: "Educação Musical no Programa Cordas da Amazônia: violoncelo para crianças e adolescentes com autismo, dislexia e TDAH" (Paiva; DeFreitas, 2014). Tais verificações denotam a necessidade de consistência na área para estruturação de resumos.

Todos os títulos teceram referência à música e tiveram como palavraschave, a depender dos seus objetivos, os seguintes descritores: desenvolvimento musical, aprendizagem musical em família, música, educação musical, aulas de música, e musical. A variedade de termos em publicações difundidas em fontes voltadas à educação musical denota a necessidade de consenso acerca do termo que melhor poderia ser utilizado como descritor às propostas que envolvam as atividades musicais educacionais. Pode-se sugerir que, pelo fato de se tratar de uma ciência pedagógica, o uso do termo "educação musical" torna-se mais adequado para determinar estas práticas.

Quanto aos objetivos das pesquisas, dos 16 artigos, 12 são voltados à análise, reflexão ou exploração de processos para o desenvolvimento e aprendizagem musical: Dias (2011); Rodrigues, DeFreitas e Silva (2011); Borges e Monteiro (2012); Oliveira et al. (2012); Soares (2012); Afonso (2013); Oliveira, Rezende e Parizzi (2013); Queiroz (2013); Rodrigues e DeFreitas (2013); Gomes (2014); Paiva e DeFreitas (2014); Candemil e Muller (2016); e quatro referentes a alcances secundários da música, a saber: Rodrigues e Pereira (2011); Rodrigues, Pereira e DeFreitas (2012), desenvolvimento global; Alves (2014), desenvolvimento intelectual e integração social; e Blumer (2016), interseção entre a clínica psicomotora e a educação musical. Deve-se ressaltar, entretanto, que estas produções também mostram informações relevantes que colaboram para a prática do professor de música.

Louro (2012) defende que, para atender educacionalmente as pessoas com deficiência de forma satisfatória, o professor deve ter um conhecimento pormenorizado do aluno. Dos 16 artigos analisados, somente dois $(12,5 \%)$ indicaram ferramentas voltadas ao levantamento do perfil do aluno e deixaram explicita esta etapa antes do trabalho de educação musical para alunos com TEA. Rodrigues, DeFreitas e Silva (2011) indicaram a realização de uma entrevista semiestruturada com os responsáveis, levantando-se dados sobre: principais características apresentadas pelos estudantes em sua vida diária, comportamento em grupo, reação ao contato físico, reação ao barulho, atendimento aos comandos, dificuldades de visão e audição, presença de estereotipias e convulsões. Já Rodrigues e Pereira (2011) indicaram para esta finalidade o uso da Escala de Áreas de Aquisição do Desenvolvimento Global, adaptada de Pereira (2004). 
Considerando-se que somente $12,5 \%$ da produção científica levantada contemplou este quesito, atenta-se à necessidade de professores(as) e pesquisadores(as) se apropriarem de ferramentas que lhes deem pontos de partida para o trabalho com seu público-alvo. No caso de alunos com TEA, são possivveis a hiper e hiporreatividade, dificuldades comportamentais e a presença de comportamentos repetitivos, aspectos que, se conhecidos, auxiliam professor e pesquisador a planejarem melhor seu trabalho e a saberem lidar com o aluno. Conhecer as preferências e o que desagrada os alunos também é primordial, pois da mesma forma contribui à formulação de atividades, promoção de engajamento e motivação, informações, portanto, relevantes para uma condução de aprendizagem que respeite o perfil do aluno e suas habilidades, contribuindo assim para seu crescimento educacional.

Para Louro (2012), o professor deve adotar estratégias diferenciadas para as aulas e avaliações. O primeiro quesito, estratégias diferenciadas para as aulas, pode ser contemplado pelo conhecimento do perfil do aluno (aspecto problematizado anteriormente), conjuntamente à habilidade do(a) professor(a)/pesquisador(a) em planejar atividades com respaldo num conhecimento científico da pedagogia musical. Dos 16 estudos analisados, sete $(43,75 \%)$ indicaram elementos pedagógicos necessários para o ensino de música a alunos com TEA.

O modelo de ensino tradicional encontra-se presente em muitas escolas de música e é marcado por um currículo que deve ser seguido à risca em um período específico. Paiva e DeFreitas (2014) e Oliveira et al. (2012), embora defendam que a rotina prevista no ensino tradicional de música seja importante ao aluno com TEA, ressaltam, para sua organização, que se deve respeitar o tempo de aprendizagem deste, fornecer comandos claros e trabalhar a teoria na prática, fazendo as adaptações necessárias para o mesmo apreender o que for trabalhado em sala.

A rotina estruturada é um fator relevante ao público com TEA, pois pode tornar o ambiente familiar ao aluno; os elementos de preferência deste também podem contribuir para isso, se incorporados à rotina, gerando assim mais engajamento e motivação. Entretanto, Paiva e DeFreitas (2014) atentam ao fato de que os objetivos musicais traçados devem ser gradualmente mais complexos a cada novo estudo e nova canção, de forma que o aluno evolua.

Atividades que envolvem o trabalho da rítmica também se revelaram como estratégia promissora para compor as aulas de alunos com TEA, podendo-se ter contato com diversas propostas: variações timbrísticas e métrica, performance e ritmo (Oliveira; Rezende; Parizzi, 2013; Dias, 2011); percepção musical e ritmo (Queiroz, 2013); uso de canções e instrumentos musicais a partir de imagens, sons, linguagem e ritmo (Afonso, 2013); ditado rítmico-melódico de alturas e ditados rítmicos (Soares, 2012). Este último estudo ressalta a possibilidade de se direcionar comportamentos repetitivos que porventura se apresentem em alunos com TEA, utilizando-se para isso a 
pulsação, o que pode auxiliar o aluno a se regular no ambiente e atribuir funcionalidade musical ao movimento repetitivo apresentado.

Estratégias diferenciadas na abordagem à teoria musical também puderam ser encontradas nesses estudos. Para trabalhar altura musical, Queiroz (2013) indica a utilização de copos de água das alturas de Dó a Si, porém não fornece ao leitor esclarecimentos sobre como fazer isso. O melhor detalhamento da metodologia utilizada mostrou-se, portanto, imprescindivel para subsidiar os resultados defendidos.

Soares (2012), por sua vez, propõe o trabalho de acidentes (sustenido e bemol), a partir da utilização de uma escada feita com caixas, em que cada degrau corresponde a um acidente, e um objeto deve ser guiado pelo som e colocado no respectivo degrau. A autora defende, ainda, o uso de dicas visuais, recurso muito utilizado em tratamento de crianças com TEA, especialmente aquelas com fala não preservada. Em sua proposta para o estudo de escalas maiores, indica a utilização do piano e letras indicativas $\mathrm{T}$ (representando tom) e ST (representando semitom), em atividade em que o aluno deve ouvir e apontar a ficha correspondente. Já para o trabalho da apreciação, indica o uso de imagens de instrumentos em cartelas, os quais são marcados pelo aluno após ouvir seus respectivos sons. Para a prática coral, propõe a adaptação de partituras com figuras para ajudar a organizar a música e memorizar a letra.

Afonso (2013), por sua vez, indica a elaboração e adaptação de atividades com base no Método Kodály (subdivisões rítmicas substituídas por imagens com grafias dos ritmos semelhantes à grafia rítmica tradicional, trabalhandose inicialmente por imitação, combinando duração do som e grafia), bem como de atividades com base no Método Orff, com foco na linguagem inserindo o uso de imagem e nome dos animais, canções preferidas do aluno e inserção de outros repertórios, nomes próprios, rimas, canções infantis e poemas com padrões rítmicos, improvisações e atividades corporais e de instrumental Orff.

Candemil, Silva e Muller (2016) também defendem que o uso de cartelas com imagens ilustrativas é eficiente nas atividades musicais para orientar tarefas. Essa prática foi proposta por estes autores baseando-se no método Treatment and Education of Autistic and related Communication-handicapped Children (TEACCH), que visa auxiliar o alcance de autonomia e melhorias de comunicação no relacionamento com o outro e na aprendizagem. Na educação musical, desenvolver objetivos secundários também se faz necessário, e isso não significa não ensinar música musicalmente ou fazer uso dela para finalidades não educacionais de música.

Assim como nas séries iniciais da escola regular, onde é mais perceptivel o ensino de conteúdos atrelados à busca do desenvolvimento de vários aspectos (ex., coordenação motora, desenvolvimento social e da linguagem etc.), ensinar música deve considerar a maturidade do discente e o trabalho de áreas diversas, conjuntamente, para que a apreensão da teoria e da prática 
seja, de fato, possível. Esta ideia pode ser encontrada em 31,25\% dos estudos nesta pesquisa.

Blumer (2016) defende que propostas musicais que permitam o trabalho de aspectos da psicomotricidade (psicológico, cognitivo, motor e etário) são essenciais a pessoas com TEA, isso porque, ao desenvolver conjuntamente esta área, pode-se alcançar melhorias substanciais em ritmo e pulsação, por exemplo. Rocha e Boggio (2013), por sua vez, enfatizam que alunos com TEA podem aumentar conexões neuronais em áreas diversas (comunicação, interação social e motricidade) quando expostas a experiências musicais, que são habilidades também requeridas no processo de aprendizagem musical.

Rodrigues e Pereira (2011) também defendem o trabalho de atividades musicais que explorem aspectos diversos (psicomotor, cognitivo, linguagem, socialização e atividade de vida diária). Para estes autores, tal trabalho contribui com o processo global de aprendizagem e melhora a orientação do aluno e a sua compreensão das demandas de atividades.

Oliveira, Rezende e Parizzi (2013), por sua vez, apresentam uma proposta muito interessante que une música e movimento: o uso de atividades de movimentação corporal para o aumento de vocalizações e para a ampliação da extensão melódica. Já Gomes (2014) defende que se deve proporcionar a aprendizagem e o desenvolvimento da inteligência musical fazendo-se música em aula de música, o que é possível por meio de atividades como audição, canto, representação, reprodução, criação, composição, improvisação, movimento, dança e execução instrumental, entre outras. Todos esses estudos, portanto, deixam clara a importância do planejamento de atividades que envolvam vários aspectos do desenvolvimento para que a aprendizagem musical seja alcançada.

Ainda sobre estratégias diversificadas para as aulas, Afonso (2013) defende que o profissional que ensina teoria musical deve apreender conhecimentos sobre os períodos de desenvolvimento musical utilizando-se de teorias de autoras como, por exemplo, Esther Beyer. Conhecer as características desenvolvimentais previstas em faixas etárias específicas permite ao docente adequar o melhor formato de apresentação de conteúdo, e isso também deve considerar o conhecimento do perfil do aluno para que se fundamente de forma científica as adaptações que porventura sejam necessárias.

Deve-se ponderar que o trabalho de aspectos do Método Suzuki, como a inicialização com o estímulo ao ouvido e à prática no instrumento antes do treino de leitura; o engajamento dos pais como colaboradores e incentivadores dos filhos; participações periódicas dos pais em sala, aulas participativas, a atuação dos alunos mais avançados como monitores dos iniciantes característica presente no String Project ${ }^{1}$ - são técnicas defendidas por Paiva

\footnotetext{
${ }^{1}$ O String Project (Projeto Cordas) visa: a) preparar os estudantes de música da universidade para o futuro como professores de escolas públicas; e b) oportunizar a alunos iniciantes o ensino de violino, viola ou
} 
e DeFreitas (2014) como promissoras à aprendizagem. Os resultados destes estudos confirmam que a diversidade na abordagem de conteúdos em sala de aula pode resultar no alcance de uma aprendizagem musical satisfatória em pessoas com TEA.

Sobre estratégias diferenciadas para as avaliações, somente cinco artigos $(31,25 \%)$ apresentaram propostas avaliativas: dois com instrumentos padronizados e três com propostas de avaliações contínuas. Rodrigues e Pereira (2011) trabalharam com a "Escala de Verificação do Aprendizado Musical para Violoncelo", e Oliveira, Rezende e Parizzi (2013), com o "Protocolo de Avaliação do Desenvolvimento Musical de Crianças Portadoras de TEA". A escassez de instrumentos padronizados para avaliações na educação musical pode ser constatada neste estudo, o que revela a necessidade de aliar pesquisa e desenvolvimento nesta área, a fim de viabilizar o construto de instrumentais avaliativos. A validação destes também é de extrema relevância para que seja possivel o alcance de resultados fidedignos estatisticamente.

Quanto às propostas de avaliações contínuas, Rodrigues, DeFreitas e Silva (2011), por sua vez, indicaram como proposta avaliativa o preenchimento de relatório diário de observação (nos dias das aulas) e enumeração das dificuldades e das facilidades de aprendizado de cada estudante; Candemil, Silva e Muller (2016) propuseram a adoção de relatórios semanais para refletir e reestruturar as ações previstas nos planos de aula; e Soares (2012), por conseguinte, indicou a adoção de levantamentos de expectativas e necessidades do aluno em relação ao curso por meio de conversas ou testes, porém não delimitou quais testes.

As propostas de avaliações contínuas apresentam olhar mais descritivo sobre a evolução de aprendizagem do discente e denotam uma maior proximidade com o aluno para delineamento de suas reais necessidades. Rodrigues, DeFreitas e Silva (2011) defendem, ainda, a manutenção da configuração de aula nas avaliações (aulas em grupo, avaliações em grupo. Isso porque, nestes casos, a migração para avaliação individual quebra a rotina do aluno com autismo e, dadas as mudanças envolvidas, pode gerar a baixa de desempenho.

Um dos aspectos que também se mostrou relevante ao ensino foi o cuidado com a configuração das aulas e do ambiente. Rodrigues, DeFreitas e Silva (2011) sugerem que o primeiro mês deva ser voltado à adaptação, visto que o aluno com TEA não apresenta seguimento significativo das atividades propostas no primeiro mês. Defendem também a inclusão dos pais no

violoncelo. São fornecidas instruções, por meio de aulas em grupo e sequência de ensaios de orquestra de câmera aos jovens estudantes, para realizarem seus próprios recitais ao final de cada semestre. Os alunos de cordas se beneficiam com aulas animadas, e os estudantes de música da universidade, que estão aprendendo a ser professores, passam a obter uma inestimável experiência de ensino com aprendizagem supervisionadas (Missouri String Project, 2018). 
ambiente da aula nas duas primeiras semanas, visto que podem aprender e reforçar o aprendizado em casa. Além disso, são um elemento conhecido, possibilitam mais segurança ao aluno e contribuem para que ele se sinta mais à vontade no novo ambiente.

Garantir a atenção do aluno com TEA também é um aspecto importante no processo de aprendizagem. Rodrigues e DeFreitas (2013) reforçam a necessidade de um ambiente agradável de educação musical para proporcionar o aumento da atenção às tarefas, bem como acesso e compreensão das informações. Gomes (2014) reforça que devemos apresentar as tarefas somente quando a criança atende, de forma clara, indicando que, quando necessário, também se pode adotar procedimentos de ajuda e se utilizar sempre de reforçadores contingentes, imediatos e potentes (elogios etc.). Borges e Monteiro (2012), por sua vez, indicam que a utilização de materiais concretos e visuais para trabalhar composição, partitura, altura, durações e timbres sonoros pode atrair a atenção dos alunos e proporcionar melhor assimilação dos parâmetros sonoros e códigos musicais (ex. barbantes pintados, papéis coloridos, fios de lã, fitas coloridas, dentre outros).

No que compete à adaptação das aulas para alunos com TEA, Soares (2012) defende que a flexibilização curricular é necessária para trabalhar conteúdos voltados às possibilidades cognitivas atuais do aluno. Além disso, aulas individuais de rítmica e estruturação são relevantes, pois se deve considerar o ritmo de aprendizagem e as necessidades do aluno, apresentando o mesmo conceito de diversas formas, permitindo, assim, que cada aluno tenha a oportunidade de compreendê-lo e assimilá-lo.

De forma geral, os artigos revelaram discussões promissoras e norteadoras ao trabalho de ensino musical para pessoas com TEA. No entanto, deve-se atentar para o fato de que o baixo número de produções, em um universo de artigos das revistas e eventos consultados, revelou a necessidade de maior divulgação das pesquisas, melhor delineamento de seus métodos e a inclusão dos anais não presentes nos sites.

\section{CONCLUSÕES E RECOMENDAÇÕES}

Os dados levantados revelam a necessidade de os profissionais se apropriarem mais das informações acerca dos seguintes aspectos: compreensão do quadro clínico; teorias do desenvolvimento humano; teorias do desenvolvimento musical; conhecimento do perfil do aluno; capacitação para adaptações curriculares; e disponibilização de um ambiente e suporte humanos que respondam às necessidades do educando e que possam colaborar com seu processo de ensino-aprendizagem.

Sabe-se que, embora seja atribuído ao professor o grande papel de formador, a política de inclusão ainda está sendo absorvida pelas instituições de ensino, mas estas precisam contribuir para que seja possivel realizar o que os autores apontaram como primordiais à boa prática do professor, a saber: 
levantamento da expectativa do professor sobre o ensino da pessoa com deficiência; propostas de sensibilização de profissionais e colegas de classe; formação de professores com domínio de conhecimentos, linguagem e manejo adequado da pessoa com deficiência; acesso a materiais didáticos adaptados e reuniões de avaliações e planejamento de ensino regular, envolvendo a equipe profissional e os pais.

Quanto ao uso da teoria musical, foi importante perceber a necessidade de o profissional conhecer os períodos de desenvolvimento musical, ou seja, compreender como apresentar conteúdos respeitando a maturidade cognitiva e desenvolvimental de cada faixa etária. Além disso, propostas que possam ser seguidas com os métodos Kodály, Orff, Suzuki, String Project, Dalcroze e Willems mostraram-se primordiais, pois consideram aspectos do desenvolvimento humano juntamente a parâmetros musicais, possibilitando, assim, a otimização da aprendizagem da pessoa com deficiência.

Indicações de estruturações de atividades também se revelaram interessantes, pois permitirão ao leitor pensar, por meio dessas propostas, estratégias para suas aulas. Além disso, discutir sobre as propostas de atividades musicais abre um leque para o olhar e para a adaptação das atividades que são utilizadas pelos profissionais de educação musical, sendo pertinentes as dicas para um estudo que potencialize esta aprendizagem e a organização das aulas.

Embora os resultados deste estudo possam servir de subsidio para leitores e profissionais interessados no ensino musical para pessoas com TEA, este não é conclusivo, pois, além da impossibilidade de acesso a todos os anais de eventos da ABEM (no período de 2006 a 2016), muitos estudos e ações podem estar sendo desenvolvidos sobre esta temática sem que sejam publicados, devendo-se, portanto, além de encorajar pesquisadores a fazer ciência, divulgando suas pesquisas, cobrar dos responsáveis pelos sites de veiculação da área a disponibilização dos anais omitidos para acesso à comunidade.

Deve-se ressaltar que, embora esta pesquisa não esgote as discussões acerca do tema, a aplicabilidade das dicas encontradas nos artigos depende de uma ação múltipla guiada pela parceria de governos, instituições, profissionais e famílias. Logo, essas propostas só atingirão plenitude quando seus agentes atuarem de forma harmônica e seguirem, conjuntamente, em direção à real política de inclusão, a qual deve respeitar profissionais, família e alunos, resguardando-os de todos os aparatos necessários para a execução fidedigna que um trabalho inclusivo requer.

\section{REFERENCIAS}

AFONSO, Lucyanne de Melo. Música e Autismo: práticas musicais e desenvolvimento sonoro musical de uma criança autista de 5 anos. In: CONGRESSO NACIONAL DA ASSOCIAÇÃO BRASILEIRA DE EDUCAÇÃO 
MUSICAL, 21., 2013, Pirenópolis. Anais... Pirenópolis: ABEM, 2013. p. 1396-1405.

ALVES, Daniella Camargos. Educação Musical e inclusão: a importância das aulas de música para a criança autista. In: ENCONTRO REGIONAL SUDESTE DA ABEM, 9., 2014, Vitória. Anais... Vitória: ABEM, 2014. p. 1530-1541.

AMERICAN PSYCHIATRIC ASSOCIATION - APA. Manual Diagnóstico e Estatístico de Transtornos Mentais DSM-5. 5. ed. Porto Alegre: Artmed, 2014.

ASSOCIAÇÃO BRASILEIRA DE EDUCAÇÃO MUSICAL. Anais dos Encontros Regionais. Disponivel em:

$<$ http://abemeducacaomusical.com.br/anais_abem.asp>. Acesso em: 5 mar. 2016.

BLUMER, Caroline. A Educação Musical aliada à clínica psicomotora e a construção simbólica no trabalho com pessoas com Transtorno do Espectro Autista (TEA). In: CONGRESSO DA ASSOCIAÇÃO NACIONAL DE PESQUISA E PÓS-GRADUAÇÃO EM MÚSICA, 26., 2016, Belo Horizonte. Anais... Belo Horizonte: ANPPOM, 2016.

BORGES, Beatriz Mauler; MONTEIRO, Glenda da Rocha. Educação Musical Infantil e Autismo: uma proposta de ensino. In: ENCONTRO REGIONAL NORTE DA ABEM, 7., 2012, Belém. Anais... Belém: ABEM, 2012. p. 330346.

CANDEMIL, Luciano da Silva; SILVA, Josiane Vitôr da; MULLER, Cristiane. Jardim En-Cantado: materiais didáticos para alunos com transtorno do espectro autista. In: CONGRESSO DA ASSOCIAÇÃO NACIONAL DE PESQUISA E PÓS-GRADUAÇÃO EM MÚSICA, 26., 2016, Belo Horizonte. Anais... Belo Horizonte: ANPPOM, 2016.

DIAS, Sheila Cristina Escudeiro Hernandes. Aprendizagem musical no ambiente familiar e a Sindrome de Asperger: reflexões a partir de uma cena. In: CONGRESSO NACIONAL DA ASSOCIAÇÃO BRASILEIRA DE EDUCAÇÃO MUSICAL, 20., 2011, Belém. Anais... Belém, 2011.

GERHARDT, Tatiana Engel; SILVEIRA, Denise Tolfo. Métodos de Pesquisa. Porto Alegre: Editora da UFRGS, 2009.

GOMES, Hendy Anna Oliveira. Autismo e Educação Musical. In:

ENCONTRO REGIONAL SUDESTE DA ABEM, 9., 2014, Vitória. Anais... Vitória: ABEM, 2014. p. 1530-1541.

LOURO, Viviane. Fundamentos da aprendizagem musical da pessoa com deficiência. 1. ed. São Paulo: Editora Som.

OLIVEIRA, Gleisson do Carmo; REZENDE, Vanilce Peixoto de Morais; PARIZZI, Maria Betânia. Criança autista e Educação Musical: um estudo exploratório. In: CONGRESSO NACIONAL DA ASSOCIAÇÃO BRASILEIRA 
DE EDUCAÇÃO MUSICAL, 21., 2013, Pirenópolis. Anais... Pirenópolis: ABEM, 2013. p. 754-763.

OLIVEIRA, Glaucia Freire de; NASCIMENTO, Paulyane Silva do; DEFREITAS, Áureo Déo; AMBÉ, Geyze. Música e Inclusão: relato de experiência em uma turma de percussão infantil Educação Musical Infantil e Autismo: uma proposta de ensino. In: ENCONTRO REGIONAL NORTE DA ABEM, 7., 2012, Belém. Anais... Belém: ABEM, 2012. p. 338-337.

PAIVA, Adriana Catarina de Carvalho de; DEFREITAS, Áureo Déo. Educação Musical no Programa Cordas da Amazônia: violoncelo para crianças e adolescentes com autismo, dislexia e TDAH. In: ENCONTRO REGIONAL NORDESTE DA ABEM, 12., 2014, São Luis. Anais... São Luis: ABEM, 2014.

PLATAFORMA SUCUPIRA. Qualis Periódicos. Disponivel em: <https://sucupira.capes.gov.br/sucupira/public/consultas/coleta/veiculoP ublicacaoQualis/listaConsultaGeralPeriodicos.jsf>. Acesso em: 5 mar. 2016.

QUALIS. In: FUNDAÇÃO CAPES MINISTÉRIO DA EDUCAÇÃO, nov. 2017. Disponivel em: <http://www.capes.gov.br/acessoainformacao/perguntasfrequentes/avaliacao-da-pos-graduacao/7422-qualis>. Acesso em: 5 dez. 2017.

QUEIROZ, Isabela Cristina Sousa. O autismo: aspectos gerais e um breve relato de experiência. In: CONGRESSO NACIONAL DA ASSOCIAÇÃO BRASILEIRA DE EDUCAÇÃO MUSICAL, 21., 2013, Pirenópolis. Anais... Pirenópolis: ABEM, 2013. p. 1530-1541.

ROCHA, Viviane Cristina da; BOGGIO, Paulo Sérgio. A música por uma óptica neurocientífica. Per Musi, Minas Gerais, n. 27, p. 132-140, jan. 2013. Disponivel em: <http://www.scielo.br/pdf/pm/n27/n27a12.pdf >. Acesso em: 5 jul. 2016.

RODRIGUES, Jessika Castro; DEFREITAS, Áureo Déo. Um Estudo do Processo de Inclusão de Pessoas com Transtorno do Espectro do Autismo na Escola de Música da Universidade Federal do Pará: Um projeto de Pesquisa. In: CONGRESSO NACIONAL DA ASSOCIAÇÃO BRASILEIRA DE EDUCAÇÃO MUSICAL, 21., 2013, Pirenópolis. Anais... Pirenópolis: ABEM, 2013. p. 2321-2332.

RODRIGUES, Jessika Castro; DEFREITAS, Áureo Déo; SILVA, Letícia. Educação Musical Inclusiva: Aulas de Violoncelo em Grupo para Crianças e Adolescentes com Diagnóstico de Autismo e sem Diagnóstico de Transtorno. In: CONGRESSO NACIONAL DA ASSOCIAÇÃO BRASILEIRA DE EDUCAÇÃO MUSICAL, 20., 2011, Vitória. Anais... Vitória: ABEM, 2011. p. 2441-2447.

RODRIGUES, Jessika Castro; PEREIRA, Cláudio Ludgero Monteiro. Desenvolvimento global do adolescente com diagnóstico de Transtorno Autista inserido em turma de educação musical para crianças e adolescentes com e sem transtorno. In: CONGRESSO NACIONAL DA 
ASSOCIAÇÃO BRASILEIRA DE EDUCAÇÃO MUSICAL, 20., 2011, Vitória. Anais... Vitória: ABEM, 2011. p. 763-773.

RODRIGUES, Jessika Castro; PEREIRA, Claudio Ludgero Monteiro;

DEFREITAS, Áureo. A Educação Musical como ferramenta de auxílio para desenvolvimento global de crianças e adolescentes com transtorno autista. In: CONGRESSO DA ASSOCIAÇÃO NACIONAL DE PESQUISA E PÓSGRADUAÇÃO EM MÚSICA, 22., 2012, João Pessoa. Anais... João Pessoa: ANPPOM, 2012. p. 119-126.

SOARES, Lisbeth. Programa de Apoio Pedagógico e Inclusão: um estudo de caso. Revista da ABEM, v. 20, n. 27, p. 55-64, jan./jun. 2012. Disponível em:

<http://www.abemeducacaomusical.com.br/revistas/revistaabem/index.ph p/revistaabem/article/view/160/95>. Acesso em: 11 out. 2016.

MISSOURI STRING PROJECT. Missouri String Project (MSP) \& Missouri Youth Orchestra (MYO). Disponivel em:

$<$ https://music.missouri.edu/cmp/missouri-string-project-msp-missouriyouth-orchestra-myo>. Acesso em: 15 out. 2018.

TRIVIÑOS, Augusto Nibaldo Silva. Introdução à pesquisa em Ciências Sociais: a pesquisa qualitativa em educação. São Paulo: Atlas, 1987. 
Paulyane Nascimento Zimmer é Psicóloga e Mestra em Teoria e Pesquisa do Comportamento pela Universidade Federal do Pará (UFPA), atua em pesquisas nas áreas de Psicologia, Educação Inclusiva e Música. É Licenciada em Música pela Universidade do Estado do Pará (UEPA) e Musicoterapeuta pela Faculdade São Fidélis (FASFI/RJ). Atualmente é discente do Doutorado em Artes da UFPA.

Jéssika Castro Rodrigues é formada no Curso Habilitação Profissional Plena de Técnico em Música Área de Artes, Instrumento Piano pelo Conservatório Carlos Gomes (IECG), graduada no Curso de Licenciatura Plena em Música pela Universidade do Estado do Pará (UEPA), Especialista em Psicologia Educacional pela Universidade do Estado do Pará (UEPA) e Mestre em Artes pela Universidade Federal do Para (UFPA). Atualmente é professora de Artes Efetiva da Secretaria Municipal de Educação de Belém (SEMEC) e Doutoranda do Programa de PósGraduação em Artes da UFPA (PPGARTES-UFPA).

Áureo Déo DeFreitas possui graduação em Violoncello Performance pela University of Missouri (Columbia, 1989), mestrado em Violoncello Performance pela Louisiana State University (Baton Rouge, 1992) e doutorado em Ph.D. em Educação Musical pela University of South Carolina (Columbia, 2005). Atualmente é professor do Instituto de Ciências da Arte da UFPA (ICA) onde ensina no âmbito do Programa de Pós-Graduação em Artes (PPGARTES) e Escola Técnica de Música (EMUFPA). Na extensão universitária, coordena a Orquestra de Violoncelistas da Amazônia (OVA) e Programa Cordas da Amazônia. Na pesquisa, coordena o Grupo de Pesquisa Transtornos do Desenvolvimento e Dificuldades de Aprendizagem (GPTDDA). Na gestão, coordena o Núcleo de Atendimento a Pessoas com Necessidades específicas (NAPNE). 